\title{
Laminar Restriction of Retinal Ganglion Cell Dendrites and Axons: Subtype-Specific Developmental Patterns Revealed with Transgenic Markers
}

\author{
In-Jung Kim, ${ }^{1,2}$ Yifeng Zhang, ${ }^{1,2}$ Markus Meister, ${ }^{1,2}$ and Joshua R. Sanes ${ }^{1,2}$ \\ ${ }^{1}$ Department of Molecular and Cellular Biology and ${ }^{2}$ Center for Brain Science, Harvard University, Cambridge, Massachusetts 02138
}

Retinal ganglion cells (RGCs), which transfer information from the eye to the brain, are heterogeneous in structure and function, but developmental studies have generally treated them as a single group. Here, we investigate the development of RGC axonal and dendritic arbors using four mouse transgenic lines in which nonoverlapping subsets of RGCs are indelibly labeled with a fluorescent protein. Each subset has a distinct functional signature, size, and morphology. Dendrites of each subset are restricted to specific sublaminae within the inner plexiform layer in adulthood, but acquire their restriction in different ways: one subset has lamina-restricted dendrites from an early postnatal stage, a second remodels an initially diffuse pattern, and two others develop stepwise. Axons of each subset arborize in discrete laminar zones within the lateral geniculate nucleus or superior colliculus, demonstrating previously unrecognized subdivisions of retinorecipient layers. As is the case for dendrites, lamina-restricted axonal projections of RGC subsets develop in different ways. For example, while axons of two RGC subsets arborize in definite zones of the superior colliculus from an early postnatal stage, axons of another subset initially occupy a deep layer, then translocate to a narrow subpial zone. Together, these results show that RGC subsets use a variety of strategies to construct lamina-restricted dendritic and axonal arbors. Taking account of these subtype-specific features will facilitate identification of the molecules and cells that regulate arbor formation.

\section{Introduction}

Retinal ganglion cells (RGCs) are the sole output neurons of the retina. Their dendrites receive synapses from bipolar and amacrine interneurons in the inner plexiform layer (IPL), their somata reside in a narrow ganglion cell layer, they express several common molecular features, and their axons travel through the optic nerve to retinorecipient structures in the brain, where they form glutamatergic synapses (Masland, 2001; Mu and Klein, 2004; Wässle, 2004; Nassi and Callaway, 2009). As a well defined and accessible neuronal type, RGCs have been a favored object for elucidating developmental, molecular, cell biological, and electrophysiological principles that apply to central neurons generally.

Despite many shared features, however, RGCs are heterogeneous in structure, function, and connectivity. Most notably, dendrites of individual RGCs are confined to one or a few fine strata within the IPL, and subsets of lamina-specified RGCs are tuned to distinct visual features (Kuffler, 1953; Famiglietti and

\footnotetext{
Received Sept. 25, 2009; revised Dec. 1, 2009; accepted Dec. 5, 2009

This study was supported by grants from National Institutes of Health to M.M., J.R.S., and I.-J.K., a Bushrod H. Campbell and Adah F. Hall Charity Fund Fellowship to I.-J.K, a Damon Runyon Fellowship to Y.Z., and a Merck Award for Genome-Related Research to I.-J.K. We thank Renate Hellmiss, Debbie Pelusi, Sara Haddad, and Laura Stoppel for advice and assistance.

Correspondence should be addressed to Joshua R. Sanes, Department of Molecular and Cellular Biology and Center for Brain Science, Harvard University, 52 Oxford Street, Cambridge, MA 02138. E-mail: sanesj@mcb.harvard.edu.

DOI:10.1523/JNEUROSCI.4779-09.2010

Copyright $\odot 2010$ the authors $\quad 0270-6474 / 10 / 301452-11 \$ 15.00 / 0$
}

Kolb, 1976; Masland, 2001; Wässle, 2004). The number of RGC subtypes and the degree to which they are discrete is unclear, but many mammalian species appear to have $\sim 20$ distinct subtypes, as judged by dendritic morphology (Rockhill et al., 2002; Sun et al., 2002; Dacey and Packer, 2003; Badea and Nathans, 2004; Kong et al., 2005; Coombs et al., 2006; Berson, 2008; Völgyi et al., 2009).

Until recently, few if any molecular markers were available to identify these RGC subtypes, so most analyses depended on nonselective labeling methods. Likewise, many developmental studies have treated RGCs as a single population. This limitation severely compromises analysis of RGC projections and development. For example, it is difficult to learn whether subtypes develop in distinct ways if they can be identified only after they have matured.

This problem is now being circumvented in mice by generation of genetically engineered lines in which RGC subsets are marked with reporter genes (Hattar et al., 2002; Kim et al., 2008; Yonehara et al., 2008; Badea et al., 2009; Huberman et al., 2009; Siegert et al., 2009). Here, we characterize the structure and function of RGCs marked in four transgenic lines, then use them to address a set of open questions about patterning and development of axonal and dendritic arbors:

(1) How do RGC dendrites become restricted to appropriate IPL sublaminae? Studies in multiple species indicate that some RGCs initially extend dendrites through multiple sublaminae, then remodel their arbors to achieve laminar specificity by an activity-dependent process, whereas others are confined 
a
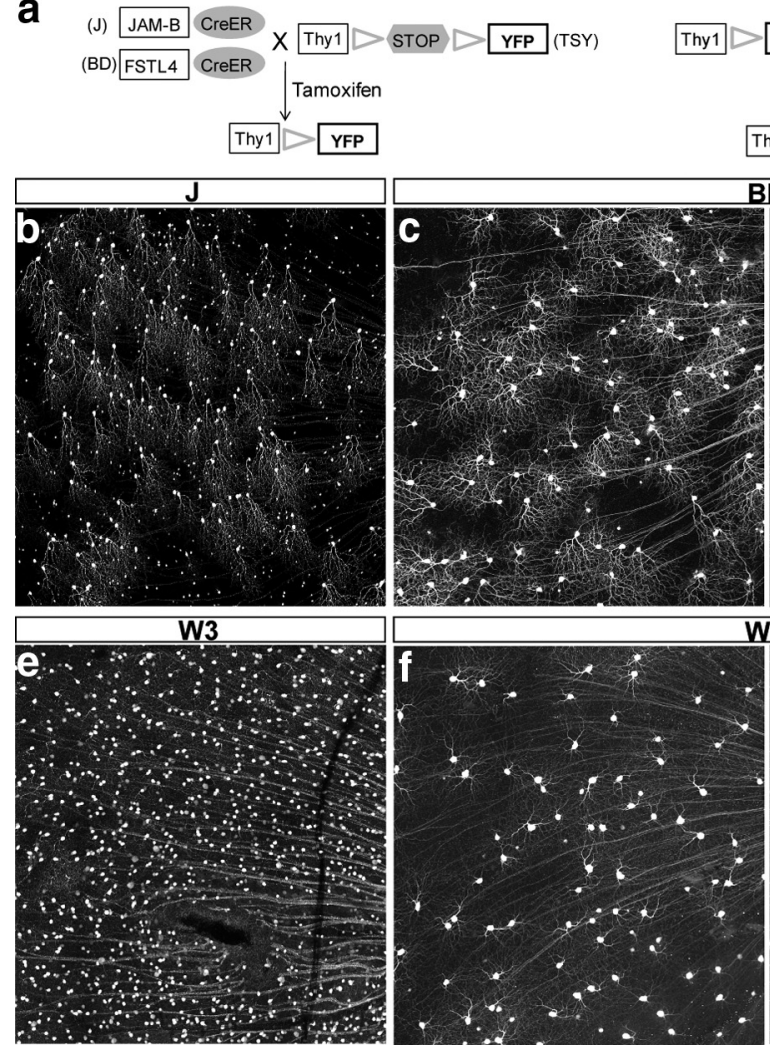

W7

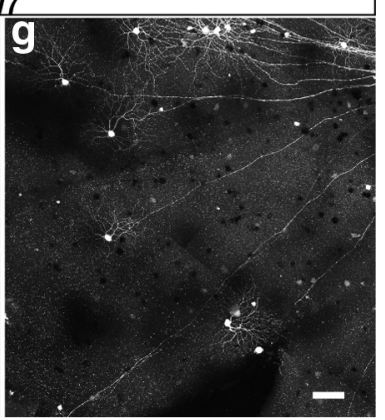

Figure 1. Transgenic lines that mark RGC subsets. $\boldsymbol{a}$, Transgenic lines used in this study. $\boldsymbol{b}, \boldsymbol{c}, \boldsymbol{e}, \boldsymbol{f}$, Portions of retinas showing YFP-marked J-RGCs in a JxTSY mouse (b), BD-RGCs in a BDxTSY mouse (c), W3-RGCs in a TYW3 mouse (e), and W7-RGCs in a TYW7 mouse $(\boldsymbol{f}) . \boldsymbol{d}, \boldsymbol{g}$, Retinas from a BDxTSY mouse (d) and a TYW7 mouse $(\boldsymbol{g})$ with reduced density of labeling resulting from manipulation of (re as shown in $\boldsymbol{a}$ and described in results. Scale bar: (in $\boldsymbol{g}) \boldsymbol{b}-\boldsymbol{g}, 100 \mu \mathrm{m}$.

Table 1. Correspondence between RGC subsets identified by transgenic markers and those categorized by morphological criteria

\begin{tabular}{llllll}
\hline This study & $\begin{array}{l}\text { Sun et al. } \\
(2002)\end{array}$ & $\begin{array}{l}\text { Coombs et al. } \\
(2006)\end{array}$ & $\begin{array}{l}\text { Kong et al. } \\
(2005)\end{array}$ & $\begin{array}{l}\text { Badea and } \\
\text { Nathans (2004) }\end{array}$ & $\begin{array}{l}\text { Völgyi et al. } \\
(2009)\end{array}$ \\
\hline J & C6 & M5a & - & 6 & G15 \\
BD & D1, D2 & 12, 13 & - & Bistratified 1, 2 & G16, G17 \\
W3 & B2 & M11 & 1 & 4 & G5 \\
W7 & A2 & M9 & 10 & 7 & G3 \\
\hline
\end{tabular}

to appropriate laminae from the outset (Maslim and Stone, 1988; Bodnarenko and Chalupa, 1993; Yamasaki and Ramoa, 1993; Bodnarenko et al., 1999; Tian and Copenhagen, 2003; Chalupa and Günhan, 2004; Diao et al., 2004; Mumm et al., 2006; Coombs et al., 2007; Xu and Tian, 2007; Tian, 2008; Yonehara et al., 2008). Here, we reconcile this apparent discrepancy by demonstrating that patterns of dendritic maturation vary systematically among subtypes.

(2) Do axons of RGC subtypes occupy discrete laminae in target areas? In lower vertebrates, the major central target of retinal axons is the optic tectum (called superior colliculus in mammals), which is divided into multiple retinorecipient laminae, each populated by arbors of distinct RGC subtypes (Yamagata and Sanes, 1995; Yamagata et al., 2006; Xiao and Baier, 2007). Likewise, the dorsal lateral geniculate nucleus (LGN) is the main target of RGCs in higher mammals, and individual laminae receive input from distinct RGC subtypes (for review, see Nassi and Callaway, 2009). In both cases, laminae are apparent with conventional histological stains, a feature that has facilitated attempts to map their inputs. In rodents, in contrast, sublaminae are not obvious in either superior colliculus or LGN, and evidence for discrete classes of axonal arbors is limited (Sachs and Schneider, 1984; Hofbauer and Dräger, 1985; Ling et al., 1998; Huberman et al., 2008, 2009; Kim et al., 2008). We show here, however, that YFP-labeled axons of four transgenic lines each occupy distinct laminar zones within the LGN or superior colliculus.

(3) How do RGC axons become restricted to appropriate retinorecipient laminae? In the LGN, retinal axons initially span laminae that are ultimately occupied by arbors from both the contralateral and the ipsilateral eye; as development proceeds, they withdraw terminals from inappropriate and expand arbors in appropriate laminae (e.g., Godement et al., 1984; Shatz and Sretavan, 1986; So et al., 1990). Little is known, however, about whether or how axonal arbors from a single eye subdivide territory within the LGN or superior colliculus. Reports to date emphasize that laminar targeting in the optic tectum of fish and birds is precise from the outset (Yamagata and Sanes, 1995; Xiao and Baier, 2007). Here, we examined axonal arbors of RGC subsets during postnatal development and show that at least some undergo substantial remodeling during this period.

Together, our results introduce new tools and techniques for analysis of visual system development, reveal a systematic relationship between laminaspecified RGC dendrites and axons, and demonstrate subtypespecific developmental patterns.

\section{Materials and Methods}

Mice. The generation of JAM-B-CreER mice has been described previously (Kim et al., 2008). Briefly, the JAM-B-CreER transgene was generated from a bacterial artificial chromosome (BAC) by insertion of a CreER cDNA at the initiation codon of the JAM-B coding sequence. The recombineering method of Lee et al. (2001) was used to remove the loxP site from the $\mathrm{BAC}$, and to insert a frt-neo-frt cassette, Cre-ER, and a polyadenylation signal. Following generation of transgenic mice by standard methods, mice were mated to mice that expressed flp recombinase ubiquitously (Farley et al., 2000) to excise the frt-neo-frt cassette. FSTL4-CreER mice were generated by the same strategy, except that the BAC contained $\sim 128 \mathrm{~kb}$ from the FSTL4 gene, including $\sim 100 \mathrm{~kb}$ upstream and $\sim 28 \mathrm{~kb}$ downstream of the initiation codon (Children's Hospital Research Institute). JAM-BCreER and FSTL4-CreER mice were crossed to mice that express the yellow fluorescent protein (YFP) following Cre-mediated excision of sequences that block terminate transcription and translation (Thy1STOP-YFP mice line 15, called TSY here) (Fig. 1a) (Buffelli et al., 2003). Tamoxifen (100 $\mu \mathrm{g}$, Sigma) was injected intraperitoneally into double transgenics at postnatal day $0(\mathrm{P} 0)-\mathrm{P} 1$ to activate CreER and thereby initiate expression of YFP.

W3 and W7 mice were generated from a vector in which Thy1 regulatory elements drive expression of YFP, wheat germ agglutinin (WGA), and Escherichia coli $\beta$-galactosidase (LacZ; Thy1-lox-YFPSTOP-lox-WGA-LacZ) (Fig. 1a) (called TYW3 and TYW7, respectively). The transgene was intended to express WGA plus LacZ 
following excision of YFP by Cre, but neither WGA nor LacZ were expressed at detectable levels. YFP was expressed in distinct and nonoverlapping subsets of RGCs in the W3 and W7 lines, presumably due to effects of sequences near the site of transgene integration in the genome (for discussion, see Feng et al., 2000). To decrease the number of YFPpositive RGCs in these lines, an adenoassociated virus (AAV, serotype 2) that expressed Cre under the control of a CMVpromoter (Harvard Gene Therapy Core, Children's Hospital, Boston) was injected into the retina as described below.

Mice in which the regulatory elements of the Chx10 gene drive expression of Cre (Rowan and Cepko, 2004) were provided by Constance Cepko (Harvard). Chx10-Cre mice were crossed to TSY mice to label a large subset of RGCs.

Surgical procedures. Mice were anesthetized by intraperitoneal injection of ketamine/xylazine. A small hole was made in the eye with an insect pin to release intraocular pressure. Cholera toxin B subunit conjugated to Alexa Fluor $594(1-2 \mu \mathrm{l}$ of $1 \mathrm{mg} / \mathrm{ml}$, Invitrogen) or AAV2-Cre (0.1-0.5 $\mu \mathrm{l}$ of $5.2 \times 10^{12}$ genome copies $/ \mathrm{ml}$ ) was injected through the same hole using a Hamilton syringe. For injection of AAV2-Cre, a pressure injector (Harvard Apparatus) was used to control injection volume. After surgery, anesthesia was reversed by injecting antisedan, and the mice were observed for proper recovery. At appropriate times, mice were killed with sodium pentobarbital and perfused transcardially with $4 \%$ paraformaldehyde in $0.1 \mathrm{M}$ phosphate buffer (PB; pH 7.4). Procedures were approved by the animal care and use program at Harvard University.

Histology. Following perfusion, retinas and brains were dissected. For analysis of sections, retinas were postfixed for $1 \mathrm{~h}$, incubated with $30 \%$ sucrose/PBS for $2 \mathrm{~h}$, frozen, and sectioned at $20 \mu \mathrm{m}$ in a cryostat. Sections were incubated with $3 \%$ donkey serum/0.1\% Triton X-100/PBS for $30 \mathrm{~min}$, with primary antibodies overnight at $4^{\circ} \mathrm{C}$, and with secondary antibodies for $2 \mathrm{~h}$ at room temperature. For whole-mount staining, retinas were treated similarly, but incubation with primary antibodies was extended to $5 \mathrm{~d}$.

Brains were postfixed overnight at $4^{\circ} \mathrm{C}$, then prepared for sectioning. For cryostat sectioning, tissue was incubated successively with $15 \%$ sucrose/PBS and $30 \%$ sucrose/PBS overnight at $4^{\circ} \mathrm{C}$, and sectioned at $40-60 \mu \mathrm{m}$. For vibratome sectioning, tissue was postfixed overnight at $4^{\circ} \mathrm{C}$, washed with PBS, and sectioned at $60-80 \mu \mathrm{m}$. Staining proceeded as for retina sections.

Antibodies used were as follows: rabbit anti-GFP (1:500 to 1:2000, Millipore Bioscience Research Reagents), goat anti-choline acetyltransferase (1:250, Millipore Bioscience Research Reagents), and goat antivesicular acetylcholine transporter (1:1000, Promega), Secondary antibodies were conjugated to Alexa Fluor 488, Alexa Fluor 568 (Invitrogen), or DyLight 649 (Jackson ImmunoResearch) and used at 1:500.

Mice from 2-7 separate litters were examined for each line at each stage.

Electrophysiology. Mice were dark adapted for $>2 \mathrm{~h}$ before euthanasia, then the retina was isolated under an infrared microscope into oxygenated Ringer's solution ( $110 \mathrm{~mm} \mathrm{NaCl}, 2.5 \mathrm{~mm} \mathrm{KCl}, 1 \mathrm{~mm} \mathrm{CaCl}_{2}, 1.6 \mathrm{~mm}$ $\mathrm{MgCl}_{2}, 25 \mathrm{~mm} \mathrm{NaHCO}_{3}$, aerated with $95 \% \mathrm{O}_{2}, 5 \% \mathrm{CO}_{2}$ ) at room temperature. A piece of retina, $\sim 3-4 \mathrm{~mm}$ on a side, was placed with RGCs facing up in a superfusion chamber on the stage of an upright fluoresScale bar: (in $\boldsymbol{g}) \boldsymbol{a}-\boldsymbol{g}, 50 \mu \mathrm{m}$.
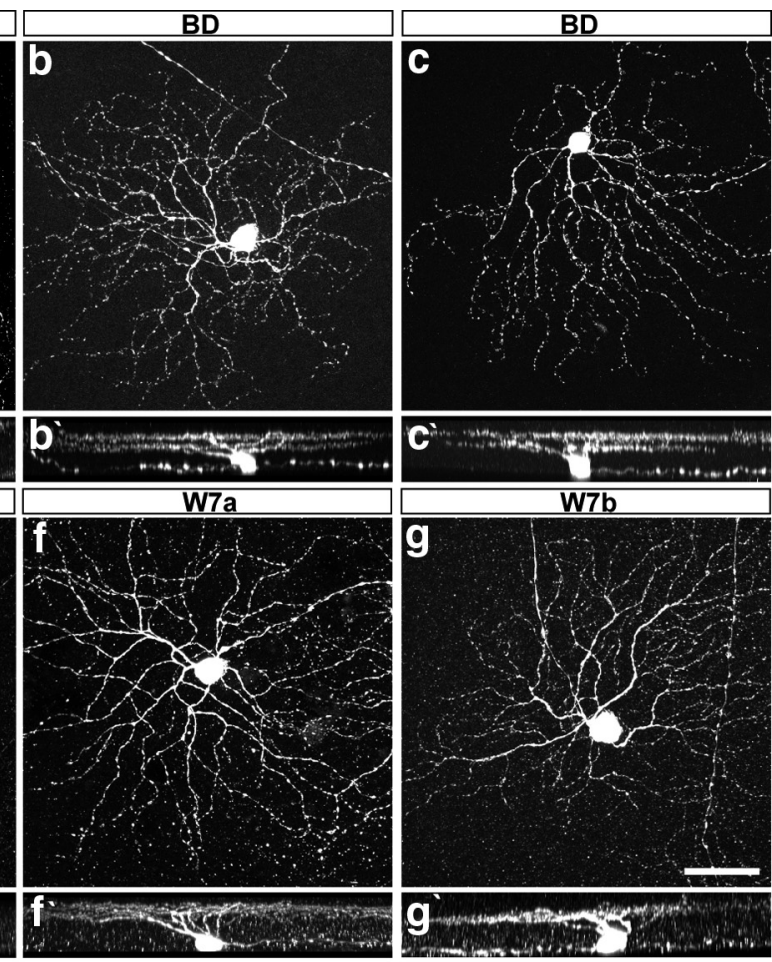

i

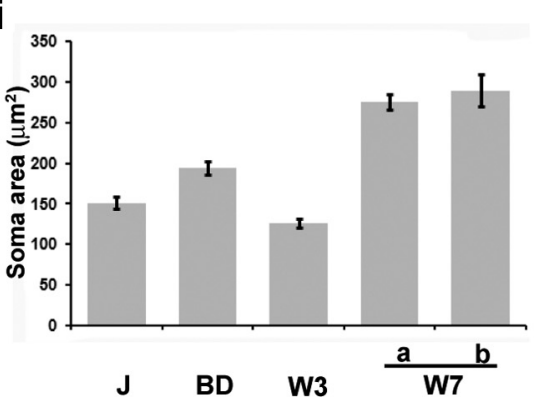

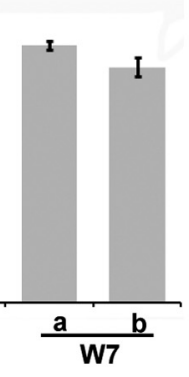

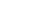

Figure 2. Morphology of J-, BD-, W3-, and W7-RGCs. $\boldsymbol{a}-\boldsymbol{g}$, Confocal stacks of J-, BD-, W3-, and W7-RGCs. W7a and W7b indicate RGCS with dendrites in SL1-SL2 and SL4 or only in SL4, respectively. $\boldsymbol{a}^{\prime}-\boldsymbol{g}^{\prime}$, Z rotations of cells shown in $\boldsymbol{a}-\boldsymbol{g}$. $\boldsymbol{h}, \boldsymbol{i}$, Dendritic field and soma areas of labeled RGCs, measured from images such as those in $\boldsymbol{a}-\boldsymbol{g}(n=13-27$ cells per type). Error bar indicates SEM.

cence microscope. Patch microelectrodes were filled with Ringer's medium and had a final impedance of 4-7 M . Fluorescent RGCs were detected by brief excitation $(\sim 20-100 \mathrm{~ms})$ with a blue LED, and then targeted for cell-attached recording.

Light stimuli were delivered from a computer-driven video projector through a custom-made substage lens system and focused onto the photoreceptors (frame rate $60 \mathrm{~Hz}$, magnification $5.75 \mu \mathrm{m} /$ pixel). White light was used, and the average intensity for all stimuli was equivalent to the following photon flux values for the three mouse photoreceptors, each expressed at the wavelength of peak sensitivity: rod, $6.7 \times 10^{4}$ photons $/ \mathrm{s} / \mathrm{cm}^{2}$ at $500 \mathrm{~nm} ; \mathrm{M}$ cone, $8.2 \times 10^{4}$ photons/ $\mathrm{s} / \mathrm{cm}^{2}$ at $511 \mathrm{~nm}$; S cone, $1.2 \times 10^{3}$ photons $/ \mathrm{s} / \mathrm{cm}^{2}$ at $370 \mathrm{~nm}$. The brief exposure for imaging with the blue LED provided the equivalent of $20-100 \mathrm{~s}$ of visual stimulation, and thus caused insignificant bleaching.

Once a tight seal was established on an RGC, we identified the receptive field center by probing with a small flashing spot, and centered all subsequent stimuli on this point. Moving spot stimuli consisted of a white square (width $115 \mu \mathrm{m}$ ) moved through the receptive field center in eight different directions consecutively, with a $0.5 \mathrm{~s}$ pause between sweeps. The tracks spanned a distance of $1150 \mu \mathrm{m}$ at a speed of $575 \mu \mathrm{m} / \mathrm{s}$. The resulting mean firing rate for each direction was graphed in a polar plot to assess direction selectivity of the response. The response to flashing spots was quantified by counting spikes in the interval between 0.1 
and $1 \mathrm{~s}$ after the onset or the offset of the flash. The optimal spot radius was obtained by fitting 3 consecutive points around the maximal response point with a quadratic function. A directional selectivity was calculated as in Kim et al. (2008). The index corresponds to the length of the vector sum, divided by the sum of all responses. It ranges from 0 for a cell with equal response in all directions to 1 for a cell that responds to only one direction.

Nomenclature. Because there is not yet an accepted classification or scheme for RGC subtypes, we refer to the subsets studied here by the names of the transgenic lines used to mark them. This practice will simplify adoption of a uniform and definitive nomenclature in the future. Tentative correspondence between the subsets we have identified and those studied by others (Sun et al., 2002; Badea and Nathans, 2004; Kong et al., 2005; Coombs et al., 2006; Völgyi et al., 2009) is summarized in Table 1.

To specify the laminar position of labeled dendrites within the IPL, we counterstained sections with Neurotrace or TO-PRO to mark the nuclear layers, and antibodies to choline acetyltransferase (ChAT), vesicular acetylcholine transporter (VAChT), or calretinin, all of which label processes of starburst amacrine cells (Haverkamp and Wässle, 2000). These cells arborize in two bands at $\sim 30 \%$ and $\sim 70 \%$ of the depth of the IPL. As suggested by Siegert et al. (2009), we divided the IPL into 10 approximately equal sectors, SL1-SL10, with SL1 abutting the inner nuclear layer, starbursts occupying SL3 and SL7, and SL10 abutting the ganglion cell layer. Anti-calretinin also stains SL5. In effect, this system divides each of the more commonly used five sublaminae (S1-S5) (Wässle, 2004) in half, except that Wässle views the ChAT/ calretinin bands as marking borders between sublaminae, whereas we place them within sublaminae.

\section{Results}

Figure 1 shows portions of retinas from each of the four lines used in this study. Complete descriptions of two subsets in adult mice [J-RGCs: Kim et al. (2008); W3 RGCs: Zhang, Kim, Sanes, and Meister (unpublished work)] are summarized briefly here for comparison. The other two subsets (BD-RGCs and W7-RGCs) have not been described previously.

To mark J-RGCs, we used mice in which regulatory elements from the JAM-B gene drive expression of tamoxifenactivated cre-recombinase (CreER). We mated JAM-B-CreER mice to mice in which Cre-dependent expression of YFP is driven by strong regulatory elements from the Thyl gene (TSY) (Fig. 1a). Following administration of tamoxifen to neonatal double transgenic mice (called JxTSY here), YFP is expressed by a subset of RGCs called J-RGCs, characterized by asymmetric arbors aligned in a dorsal to ventral direction (Fig. 1b) (Kim et al., 2008).

$\mathrm{BD}-\mathrm{RGCs}$ were marked in a line generated in parallel with the JAM-B-CreER line (Fig. 1c). We used regulatory sequences from the FSTL4 gene because we, like Yonehara et al. (2008, 2009) noted its intriguing expression pattern. Following administration of tamoxifen to FSTL4-CreER $\times$ TSY double transgenics (called BDxTSY), YFP was expressed in more RGCs in dorsal than in ventral retina, as described by Yonehara et al. (2008). However, as shown below, these BD-RGCs do not resemble those described by Yonehara et al. (2008). We presume that integration site-dependent influence led to ectopic expression of FSTL4-CreER, as has been described for numerous other transgenic lines generated by similar methods (e.g., Haverkamp et al., 2009).

W3-RGCs and W7-RGCs were marked in lines in which Thy1 drove expression of a transgene that included YFP flanked by lox sites (TYW3 and TYW7). In each line, expression was restricted to neuronal subsets, presumably as a consequence of sequences near the chromosomal site of transgene integration (Caroni,
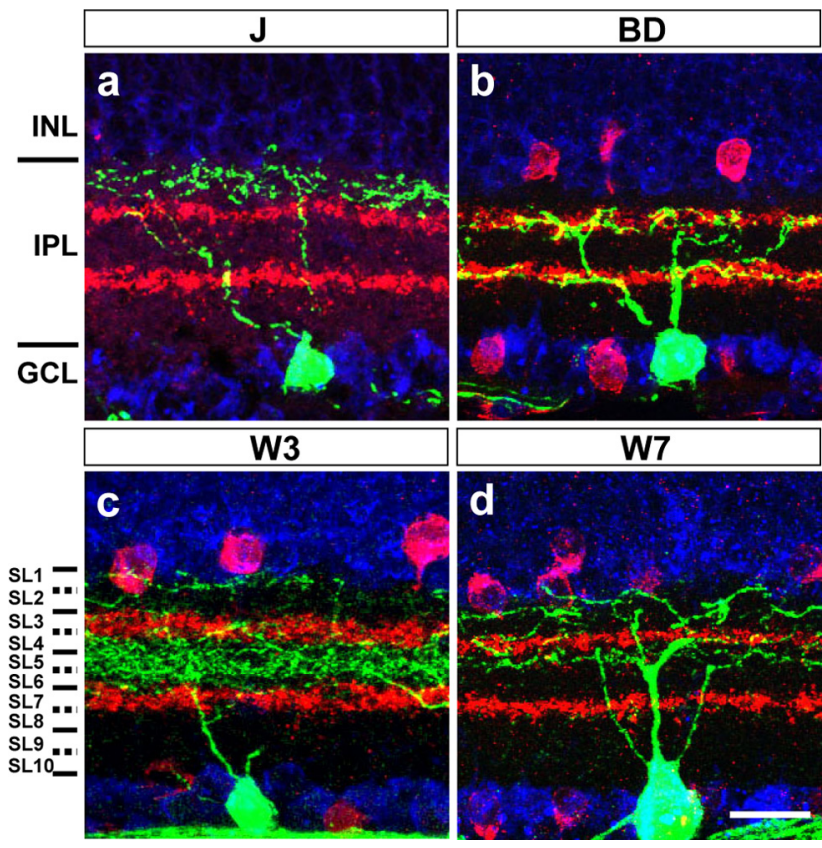

Figure 3. Lamina-restricted dendrites of J-, BD-, W3-, and W7-RGCs. RGCs were labeled with anti-GFP (green), starburst amacrines with anti-ChAT or VAChT (red), and somata with Neurotrace or T0-PRO (blue). INL, Inner nuclear layer; IPL, inner plexiform layer; GCL, ganglion cell layer. Scale bar: (in $\boldsymbol{d}) \boldsymbol{a}-\boldsymbol{d}, 20 \mu \mathrm{m}$.

1997; Feng et al., 2000). In the TYW3 line, some RGCs are labeled brightly and others dimly, and more RGCs are labeled in the ventral portion of the retina than in the dorsal side. We focused our analysis on bright cells (Fig. 1d). In the TYW7 line, YFP was expressed in a subset of large RGCs in nasal retina and a larger, less homogeneous population in temporal retina (Fig. 1e). Our analysis focused on nasal retina.

\section{Structure and function of RGC subsets}

For assessing the distribution and physiology of RGCs, it is useful to have as many members of a subset labeled as possible. In contrast, for analyzing dendritic morphology, cells must be spaced far enough apart that their arbors do not overlap. We therefore manipulated Cre recombinase to adjust the number of labeled cells (Fig. 1a). In JxTSY and BDxTSY double transgenics, increased doses of tamoxifen led to increased levels of CreER activity, which in turn led to expression of YFP in increasing numbers of labeled RGCs (Cre-on lines) (Fig. 1c,d). In contrast, in TYW3 and TYW7 mice, expression of Cre led to deletion of YFP. To decrease the number of labeled cells in these lines, we infected RGCs with an adeno-associated virus that expressed Cre, using a dose that deleted YFP from $70-$ $90 \%$ of RGCs (Cre-off lines) (Fig. $1 f, g$ ).

We reconstructed RGCs from confocal images of sparsely labeled retinas (Fig. 2) and used sections of heavily labeled, counterstained retina (see Materials and Methods, Nomenclature) to precisely define the laminar position of dendrites in the IPL (Fig. 3). We also targeted YFP-labeled cells in densely labeled retinas with cell-attached patch electrodes, and recorded visually evoked responses (Fig. 4).

$J-R G C s$

J-RGCs are strikingly asymmetric: a single primary dendrite extends ventrally, and $>90 \%$ of the dendritic field is ventral to the soma (Fig. 2a). A few J-RGCs near the dorsal and ventral margins 
are symmetrical in shape. Dendrites of both asymmetrical and symmetrical populations branch a few times in the middle of the IPL, then ascend to the outer margin, where further branches and terminal arbors reside in SL2 (Figs. $2 a^{\prime}, 3 a$ ).

As described previously (Kim et al., 2008), the functional properties of J-RGCs are closely related to their structural properties. Like most RGCs with dendritic arbors confined to the outer half of the inner plexiform layer (Wässle, 2004), they responded at light offset when a small flashing spot was positioned at the receptive field center (Fig. $4 a$ ). When the size of the flashing spot was increased gradually, the response of the J-RGCs first increased and then decreased due to the antagonistic effect of the surround (Fig. $4 e$ ). The radius of the receptive field center, as measured by the spot that elicits the strongest response, was $140 \pm 8 \mu \mathrm{m}$ (Fig. $4 m$ ). When probed with a small moving spot, the firing rate of J-RGCs varied strongly with the direction of motion (Fig. $4 i, o$ ). The preferred direction of motion corresponded to the direction of the dendritic arbor from the soma.

\section{$B D-R G C s$}

BD-RGCs are large cells with bistratified dendrites (Fig. 2b,c). Some BD-RGCs had asymmetric arbors (Fig. 2c), but their angular sectors were much broader than those of J-RGCs. In all cases, however, the dendrites costratified with processes of starburst amacrine cells in both ChAT-positive bands of the IPL (Fig. $3 b)$. Consistent with their bistratified organization, the BD-RGCs responded to a flashing spot at both the onset and the offset of the light (Fig. 4b). The optimal spot radius was $\sim 130 \mu \mathrm{m}$ for both $\mathrm{ON}$ and OFF responses (Fig. $4 f, m$ ). They had strongly direction-selective responses to moving stimuli (Fig. 4j,o). Most likely these RGCs correspond to the well studied ON-OFF direction-selective cells or a subset thereof (Weng et al., 2005; Demb, 2007).

\section{W3-RGCs}

W3-RGCs have densely branched dendrites that form the smallest arbors of the subsets under study (Fig. 2d,e). The arbors occupy a thick swath in the middle of the IPL from SL4 through SL6, the space between the two ChAT-positive bands. In addition, minor sprouts arborize in SL1 (Figs. $2 d^{\prime}, e^{\prime}, 3 c$ ). Consistent with the presence of dendritic arbors in both ON and OFF regions of the inner plexiform layer, W3-RGCs responded to a flashing spot at both the onset and the offset of the light (Fig. 4c), The optimal spot size had an average radius of $\sim 60 \mu \mathrm{m}$ for the OFF response and $\sim 80 \mu \mathrm{m}$ for the ON response (Fig. $4 g, m$ ). W3-RGCs responded to moving stimuli but showed no direction preference (Fig. $4 k, o$ ).
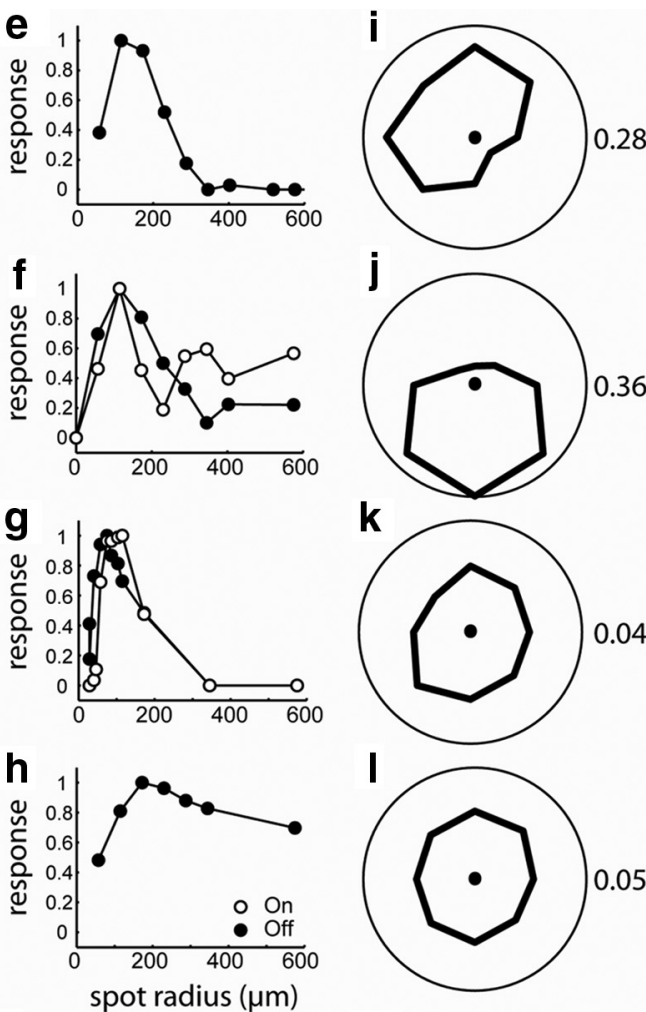

o
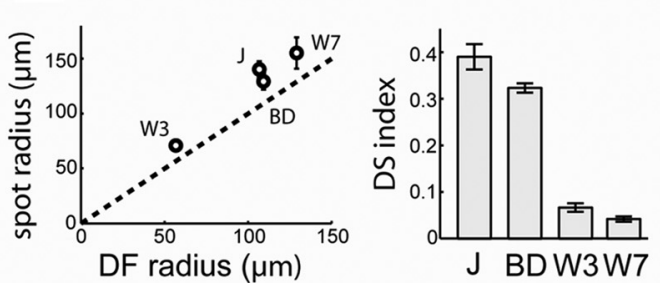

Figure 4. Visual response properties of J-, BD-, W3-, and W7-RGCs. $\boldsymbol{a}-\boldsymbol{d}$, Sample responses to a spot flashing on (white) and off (gray) over the receptive field center. Raster plot of spikes on six repeats. $\boldsymbol{e}-\boldsymbol{h}$, Responses to flashing spots as a function the spot radius. Plotted is the number of spikes during the light off (closed circles) or light on (open circles) period normalized to the maximum. $\boldsymbol{i}-\boldsymbol{l}$, Responses to small spots moving across the receptive field center in different , Error bars denote SEM. Sample size is $17,6,23$, and 15 for J, BD, W3, , ypes. Ordinate shows the radius of a circle with the same area as the dendritic field. $\boldsymbol{0}$, Direction selectivity (DS) index for each of the RGC types, calculated as described in Materials and Methods. Sample size is 16, 10, 11, and 4 for J, BD, W3, and W7, respectively. All error bars indicate SEM.

\section{W7-RGCs}

W7-RGCs have large somata and broad symmetrical dendritic arbors that stratify in SL1-SL2 and SL4 (Figs. 2f,g, 3d). Analysis of isolated RGCs revealed the existence of at least two cell types within this population: some arborize only in SL4, whereas others also extend branches in SL1-SL2 (Fig. $2 f^{\prime}, g^{\prime}$ ). W7-RGCs showed sustained OFF responses to a flashing spot (Fig. $4 d$ ) with an optimal spot radius of $\sim 155 \mu \mathrm{m}$ (Fig. $4 h, m$ ). W7-RGCs were not direction selective (Fig. 4l,o). Because their physiological properties were fairly uniform, we injected cells following recording to ask whether we had recorded from only one of the two morphological types. In fact, similar responses were characteristic of both the SL4 and the SL4 + SL1-SL2 subtypes.

Interestingly, although both the TYW3 and TYW7 lines mark at least two subtypes, each pair shares significant features. For example, the bright and dim W3-RGCs have similar 

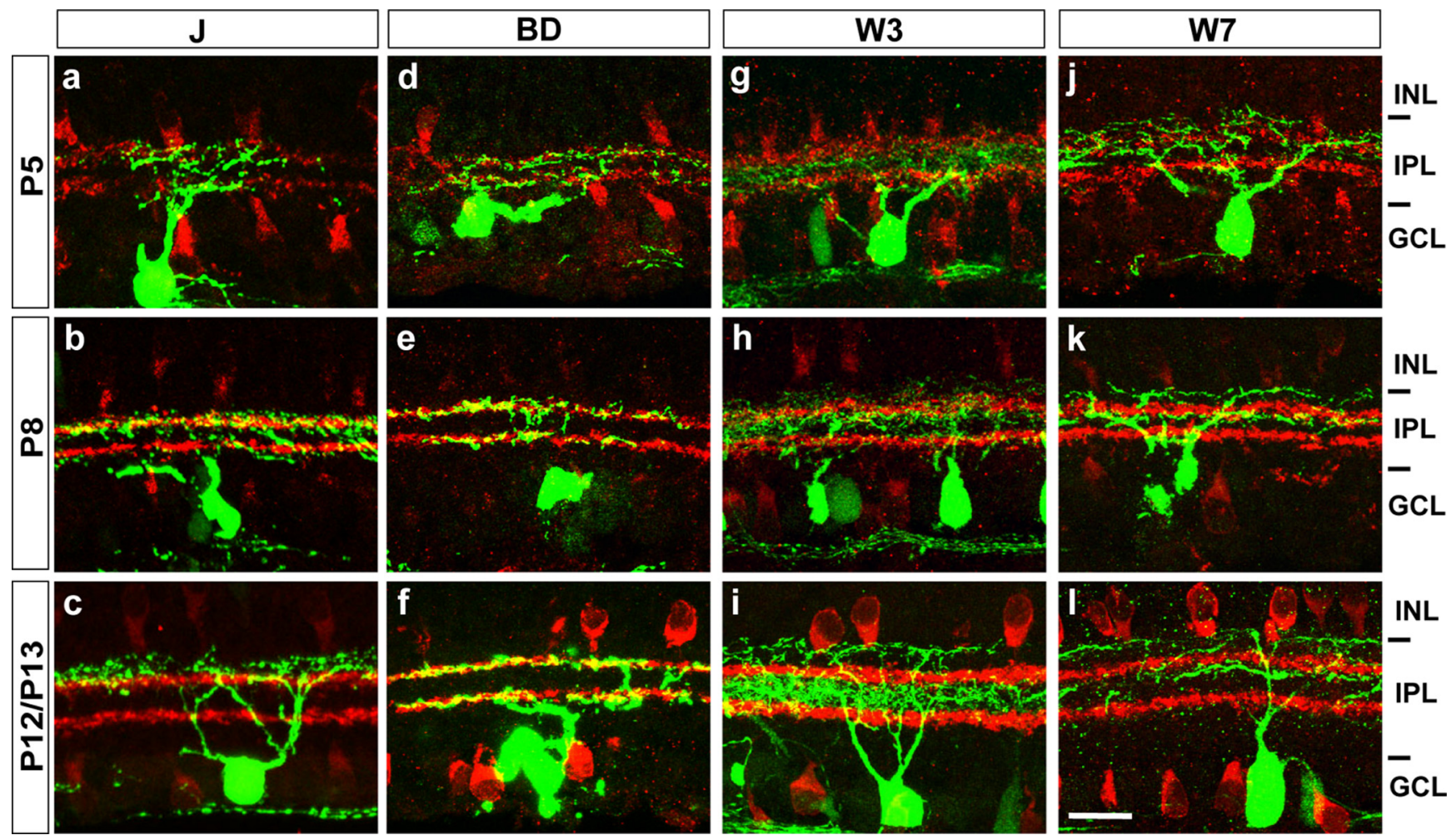

Figure 5. Subtype-specific patterns of dendritic development in the inner plexiform layer. Retinal sections were from P5, P8, and P12-P13 mice. Staining and abbreviation are as in Figure 3. All subtypes have lamina-restricted dendrites by P12-P13 (c, $\boldsymbol{f}, \boldsymbol{i}, \boldsymbol{l}$; compare with Fig. 3$)$, but the extent and nature of postnatal remodeling varies among subtypes. Scale bar: (in $I) a-I, 20 \mu \mathrm{m}$.

dendritic arbors and the two W7-RGC subsets have similar physiological responses. These shared features, together with shared transgene expression, suggest that the paired groups are closely related to each other. It will be important to identify additional transgenic or molecular markers to discriminate among these subgroups.

\section{Subtype-specific patterns of dendritic development in the inner plexiform layer}

Do RGC dendrites target IPL sublaminae in which they will ultimately arborize from the outset, or do they refine initially diffuse projections as development proceeds? To distinguish these possibilities, we analyzed retinas of the four transgenic lines from P5 to adulthood. We assessed laminar position by counterstaining with antibodies to starburst amacrines (choline acetyltransferase or the vesicular acetylcholine transporter); Stacy and Wong (2003) showed that processes of starburst amacrines form two discrete strata in the IPL by P3. We refer to these ChAT-positive bands as SL3 and SL7 in developing retina as we do in adults.

\section{$J-R G C s$}

J-RGC dendrites extended through the entire IPL at P5 (Fig. 5a). By P8, arbors were lost from the inner IPL and expanded in the outer portion of the IPL, where they were centered around processes of starburst amacrines in SL3 (Fig. 5b). Over the next several days, arbors shifted further outward; by P12, they had acquired their adult pattern of restriction to SL2 (Fig. 5c).

\section{$B D-R G C s$}

BD-RGC arbors showed much less dramatic rearrangements than those of J-RGCs. Dendrites of BD-RGCs were largely re- stricted to SL3 and SL7 by P5 (Fig. 5d). The few branches outside of these two sublaminae were removed over the next few days, so by P8, BD-RGC dendrites showed the definitive adult pattern of cofasciculation with processes of starburst amacrines (Fig. $5 e, f$ ).

\section{W3-RGCS}

W3-RGC dendrites matured in two steps. By P5, W3-RGC arbors were restricted to SL4-SL6, sandwiched between the two layers of starburst processes (Fig. $5 g$ ). Then, over the next few days, the dendritic arbor expanded outward, reaching SL1-SL2 (Fig. 5h). Finally, between P8 and P12, the proximal processes expanded within SL4-SL6, and the distal processes expanded in SL1, generating the adult bistratified pattern (Fig. 5i).

\section{W7-RGCs}

W7-RGC dendrites also matured in two steps. By P5, arbors were restricted to the outer half of the inner plexiform layer, with few if any terminals present in SL6-SL10 (Fig. 5j). At this time, however, the arbors were present throughout SL1-SL4, whereas in adults, few arbors were present in SL3 (Fig. 3d). This refinement occurred by P12 (Fig. $5 k, l$ ).

In summary, our results demonstrate marked subtypespecific variations in patterns of dendritic development, thereby helping to reconcile divergent views (see Introduction) of how maturation proceeds. The subtypes we have analyzed display adult patterns of laminar specificity by P12, just before eye opening. In some studies, however, it has been claimed that diffuse patterns become lamina-restricted only after eye opening (Tian and Copenhagen, 2003; Xu and Tian, 2007; Tian, 2008). We speculate that other subsets, yet to be found, remodel at later stages. 
Subtype-specific lamination of axonal arbors in retinorecipient zones

There has been little evidence that distinct subsets of RGCs arborize in defined sublaminae within the rodent superior colliculus and LGN. We analyzed brains of JxTSY, BDxTSY, TYW3, and TYW7 mice to reexamine this issue. To define the entire retinorecipient zone, we injected the eye with fluorophore-labeled cholera toxin B subunit (Ling et al., 1998) or used Chx10Cre/Thyl-STOP-YFP double transgenic mice in which most or all RGC subtypes are labeled (Fig. $6 a, b, k$ ). To be sure that labeled axons in the colliculus and LGN arose from RGCs, we compared the distribution of YFP in the two colliculi and geniculates of animals that had been subjected to unilateral enucleation (Figs. $6 a, c, e, g, i, 7 b, d)$, exploiting the fact that the retinal projection is predominantly crossed in rodents (Hofbauer and Dräger, 1985). In addition, we observed labeling in other known retinorecipient areas in some lines, but we have not studied these areas in enucleated animals, so we cannot be sure whether the labeling arises from RGC axons.

Axonal arbors of J-RGCs and BDRGCs occupied the superficial two-thirds of the retinorecipient zone in the superior colliculus (Fig. $6 c-f$ ). Analysis of single, isolated axons suggests that each arbor spans most or all of this region (Y. K. Hong, I.-J. Kim, and J. R. Sanes, unpublished work). W3-RGC arbors were confined to a narrower sublamina in the most superficial region, directly beneath the pia and stratum zonale (Fig. $6 g, h$ ). Axons of W7-RGCs occupied a deep region of the retinorecipient zone, beneath the region containing J- and B/D-RGC arbors (Fig. 6i,j). Finally, as noted previously (Godement et al., 1984; Hofbauer and Dräger, 1985), the sparse ipsilateral projection terminates in a deep sublamina, at or below the basal boundary of the W7-RGC arbors (Fig. 6a,k, arrows).

Projections of RGC subtypes also revealed specialization within the LGN. In the rodents, contralaterally derived retinal axons occupy a thick annulus with ipsilaterally derived axons confined to an inner core (Godement et al., 1980; Reese, 1988; So et al., 1990). Within the contralateral zone, arbors of J-RGCs were confined to a superficial region, just beneath the optic tract (Fig. $7 a)$. In contrast, arbors of BD-RGCs were largely confined to a deeper region of the LGN (Fig. 7c). We were unable to assess the location of W3- and W7-RGC axonal arbors in the LGN because many neurons within the LGN were YFP-positive in the TYW3 and TYW7 transgenic lines.

Together, these results indicate that there are at least four distinguishable termination zones for retinal axons within the retinorecipient layer of the superior colliculus (Fig. 6l) and at least three in the LGN (Fig. 7).
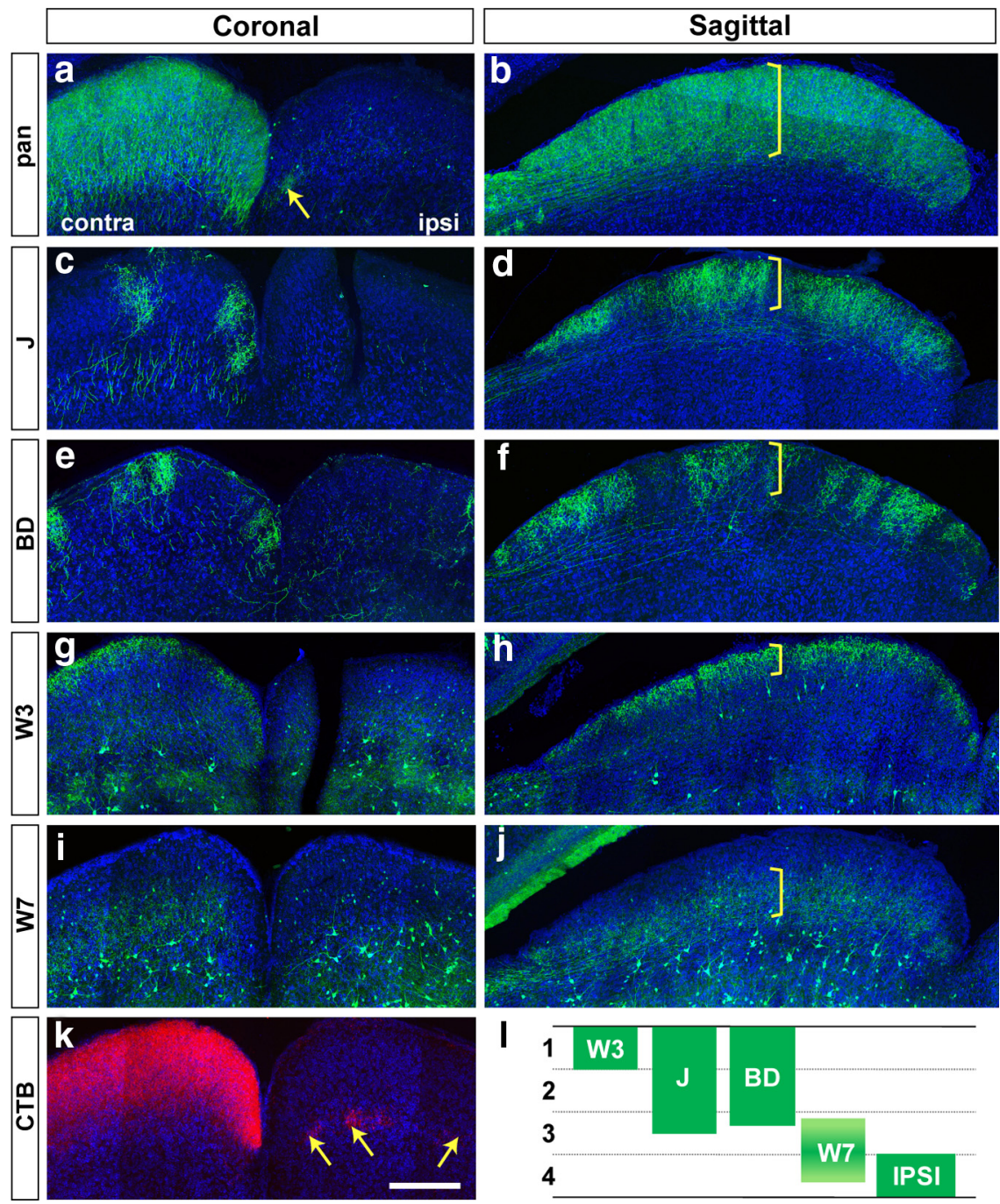

Figure 6. Lamina-restricted arbors of RGC axons within the retinorecipient zone of the superior colliculus. $\boldsymbol{a}-\boldsymbol{j}, \mathrm{Vi}-$ ratome sections were immunostained with anti-GFP (green) and counterstained with Neurotrace or T0-PRO (blue). $\boldsymbol{a}, \boldsymbol{c}_{\text {, }}$ $\boldsymbol{b}, \boldsymbol{d}, \boldsymbol{f}, \boldsymbol{h}, \boldsymbol{j}$, Sagittal sections from other mice that had not been enucleated. Brackets indicate the span of axonal arbors of GC subtypes. Transgenic lines are indicated at the left; mice were $40 \mathrm{~d}$ of age or older. $\boldsymbol{k}$, The entire retinorecipient zone SY mice in $\boldsymbol{a}$. Arrows in $\boldsymbol{a}$ and $\boldsymbol{k}$ show sparse ipsilateral projections, which terminate in a deep region. $\mathbf{l}$, Schematic showing distinct axonal restriction of each type of RGCs and ipsi projection. Scale bar: (in $\boldsymbol{k}$ ) $\boldsymbol{a}-\boldsymbol{k}, 300 \mu \mathrm{m}$.

\section{Subtype-specific patterns of axonal development in} retinorecipient zones

We assessed development of RGC axons in the superior colliculus and LGN between P5, which was as soon as labeling was sufficiently intense to be visualized, and adulthood. In both areas, arbors of J- and BD-RGCs occupied definitive laminae by P5 (Figs. $8 a-h, 9$ ). Likewise, W7-RGC axons in the superior colliculus concentrated in the deep portion of the retinorecipient zone by $\mathrm{P} 5$ (Fig. $8 m-p$ ). In this case, however, sprouts were visible in more superficial regions at P5 (Fig. $8 \mathrm{~m}^{\prime}$ ); they were lost over the next several days, leaving W7-RGC axons restricted to the deep sublamina by P12 (Fig. $8 n^{\prime}-p^{\prime}$ ).

In contrast to these subtle changes, the laminar restriction of W3-RGC axons in the superior colliculus arose by dramatic remodeling of an initial pattern. At P5, W3-RGC axons arborized in a broad band directly above the stratum opticum (Fig. 8i). By P8, the arbors had grown outward, toward the pial surface, and thus occupied a broad swath in the retinorecipient zone (Fig. 8j). Over 


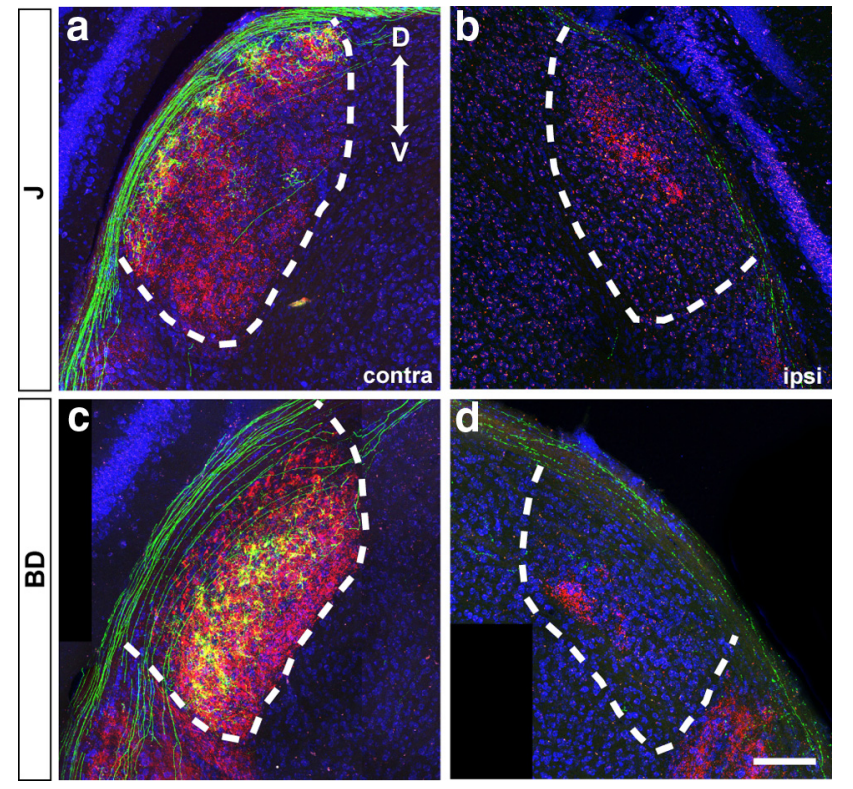

Figure 7. Lamina-restricted arbors of RGC axons in the lateral geniculate nucleus. Coronal sections were stained with anti-GFP (green) and Neurotrace (blue) after enucleation and cholera toxin administration (CTB, red). $\boldsymbol{a}, \boldsymbol{b}, \mathrm{J}$-RGCs. $\boldsymbol{c}, \boldsymbol{d}, \mathrm{BD}-\mathrm{RGCs}$. Cholera toxinpositive regions in $\boldsymbol{b}$ and $\boldsymbol{d}$ contain projections from the ipsilateral retina. D, Dorsal, $\mathrm{V}$ : ventral. Scale bar: (in $\boldsymbol{d}$ ) $\boldsymbol{a}-\boldsymbol{d}, 150 \mu \mathrm{m}$.

the next several days, the lower region of the arbors was lost or retracted (Fig. 8k), leaving W3-RGC axons restricted to a superficial sublamina by P12 (Fig. $8 l$ ).

\section{Discussion}

We have generated and characterized four transgenic lines that mark specific subsets of RGCs, and used them to provide initial answers to questions posed in the Introduction about the structure and development of dendritic and axonal arbors. In addition to subtype-specific patterns of dendritic lamination, which have been documented extensively, RGCs also have subtype-specific lamina-restricted axonal arbors in both the superior colliculus and LGN (Fig. 10). Moreover, the extent and type of postnatal remodeling leading to definitive laminar restriction varies markedly among RGC subtypes for both dendrites and axons. By focusing on specified RGC subtypes, it will now be possible to assess activity-dependent and -independent factors that regulate the form of RGC arbors and thereby help determine the synapses they make and receive.

\section{Transgenic markers of RGC subtypes}

Each of the four lines we used marks distinct RGCs, with negligible overlap among them. Morphologically, they are readily distinguished by the laminar distribution of their dendrites: SL2 for J-RGCs, SL3 + 7 for BD-RGCs, SL1 + 4-6 for W3-RGCs, and SL4 + 1-2 for W7-RGCs. Likewise, the two main functional attributes we measured physiologically were sufficient to distinguish each group from the other three: OFF direction selective for J-RGCs, ON-OFF direction selective for BD-RGCs, ON-OFF for W3-RGCs, and OFF for W7-RGCs. The size of the dendritic arbors and receptive field centers range from the smallest to the largest in the retina. These two parameters are correlated with W3-RGCs having the smallest arbors and dendritic fields, W7RGCs the largest, and J- and BD-RGCs intermediate (Fig. 4n). Together, these subsets span a wide range of the structural and functional characteristics seen in RGCs generally.

\section{Laminar restrictions in retinorecipient zones}

The optic tectum of lower vertebrates and the LGN of higher mammals are divided into multiple sublaminae that are readily distinguished by conventional histological stains and that are targeted by axons of specific RGC subtypes (Yamagata and Sanes, 1995; Yamagata et al., 2006; Xiao and Baier, 2007; Nassi and Callaway, 2009). In contrast, the retinorecipient zones of mouse superior colliculus and LGN are relatively homogeneous when viewed with conventional histological stains, and few distinctions have been documented among the RGCs that populate subdivisions within them (Sachs and Schneider, 1984; Hofbauer and Dräger, 1985; Grubb and Thompson, 2004). Transgenic lines in which RGC subsets are labeled have begun to reveal such distinctions (Huberman et al., 2008, 2009; Kim et al., 2008). Our results indicate that there are at least four distinguishable termination zones for retinal axons within the retinorecipient layer of the superior colliculus: a superficial sublamina occupied by W3-RGC axons, an intermediate zone containing the arbors of J- and B/DRGCs, a deep zone in which W7-RGCs arborize, and the deepest region, containing arbors of ipsilaterally projecting RGCs (Figs. $6 l, 10)$. Likewise, the LGN has at least three distinct zones: superficial and deep regions occupied by contralaterally derived J-RGC and BD-RGC axons, respectively, surrounding a central region occupied by ipsilaterally derived axons. Given the relatively large number of zones defined by the few transgenic lines examined to date, it seems likely that additional subdivisions exist.

It is noteworthy that RGC subsets defined in large part on the basis of their lamina-restricted dendritic arbors also display lamina-specific axonal arbors. This sort of relationship has been documented for RGCs of the M, P, and K systems, which project to distinct LGN laminae in primates (Nassi and Callaway, 2009). It has not been clear, however, whether some individual cells within a subtype defined by its dendrites would target different retinorecipient sublaminae. These alternatives have different implications for subset-specific developmental programs. For example, the same target recognition molecules could be involved in laminar-restricted formation of input and output synapses in the former case, but this would be less likely in the latter. Our results are consistent with the idea that, for any single subset, dendritic and axonal arbors are specified coordinately.

Our data also hint at a relationship between the receptive field size of an RGC and the collicular laminae in which its axons terminate. The smallest cells we studied, W3-RGCs, project most superficially, the largest, W7-RGCs, project to the deepest part of the retinorecipient zone, and the intermediate-sized RGCs, BDRGCs and J-RGCs, terminate in an intermediate position. In fact, a general relationship between RGC size and termination depth was previously noted by Hofbauer and Dräger (1985) and inferred by Sachs and Schneider (1984), so it may be applicable to multiple subtypes. In that receptive field size is related to dendritic diameter (Fig. 4n), deeper sublaminae may contain increasingly coarse representations of the visual world. The biological significance of this relationship is obscure, but may be found in the postsynaptic targets of various RGC subsets. It may also be significant that the two direction-selective RGC subsets (J-and $\mathrm{BD}$-RGCs) terminate in an overlapping region. A third directionselective RGC subset analyzed by Huberman et al. (2009) appears to terminate in the same region of the colliculus.

\section{Subtype-specific patterns of arbor maturation}

Several developmental patterns have been described for RGC dendrites, including refinement of initially diffuse arbors, formation of lamina-restricted arbors shortly after dendrites are elabo- 
rated, formation of lamina-restricted arbors that subsequently shift to more distal sublaminae, and formation of bistratified arbors in distinct steps (Maslim and Stone, 1988; Bodnarenko and Chalupa, 1993; Yamasaki and Ramoa, 1993; Bodnarenko et al., 1999; Tian and Copenhagen, 2003; Chalupa and Günhan, 2004; Diao et al., 2004; Mumm et al., 2006; Coombs et al., 2007; Xu and Tian, 2007; Tian, 2008; Yonehara et al., 2008). Although patterns may vary among species, multiple patterns have been reported even within a single species (e.g., Mumm et al., 2006; Coombs et al., 2007). We show that a major part of this diversity can be accounted for by subtype-specific developmental patterns, which range from the gradual restriction of a diffuse pattern (J-RGCs), to maturation in discrete steps (W3-RGCs and W7-RGCs), to patterns that resemble those in adults as early as we could image them (BD-RGCs). Given the striking diversity in developmental pattern, studies on mechanisms that regulate these processes (e.g., Bansal et al., 2000; Tian and Copenhagen, 2003; Liu et al., 2007; Yamagata and Sanes, 2008) are likely to be more definitive if performed using markers of specific RGC subtypes.

We also documented subtype-specific differences in the maturation of axonal arbors. There is no obvious relationship, however, between the degree to which axonal and dendritic arbors of an RGC are remodeled. For example, J-RGC dendrites remain diffuse and $\mathrm{BD}-\mathrm{RGC}$ dendrites are lamina-specified at P5, but axonal arbors of both subsets occupy definitive laminae in superior colliculus and LGN by this time. Conversely, W3-RGCs show dramatic axonal remodeling but limited dendritic remodeling during the first two postnatal weeks.

The striking postnatal rearrangement of W3-RGC axons in superior colliculus stands in sharp contrast to the modest changes observed for other cell types, and for randomly labeled RGCs in a prior study (Sachs et al., 1986). It is easy to see how this behavior was missed in studies of bulk-labeled or randomly labeled RGCs; its detection dramatizes the value of analyzing reproducibly labeled specific RGC subsets.

\section{References}

Badea TC, Nathans J (2004) Quantitative analysis of neuronal morphologies in the mouse retina visualized by using a genetically directed reporter. J Comp Neurol 480:331-351.

Badea TC, Cahill H, Ecker J, Hattar S, Nathans J (2009) Distinct roles of transcription factors brn $3 \mathrm{a}$ and brn $3 \mathrm{~b}$ in controlling the development, morphology, and function of retinal ganglion cells. Neuron 61:852-864.

Bansal A, Singer JH, Hwang BJ, Xu W, Beaudet A, Feller MB (2000) Mice lacking specific nicotinic acetylcholine receptor subunits exhibit dramatically altered spontaneous activity patterns and reveal a limited role for
$\mathbf{J}$
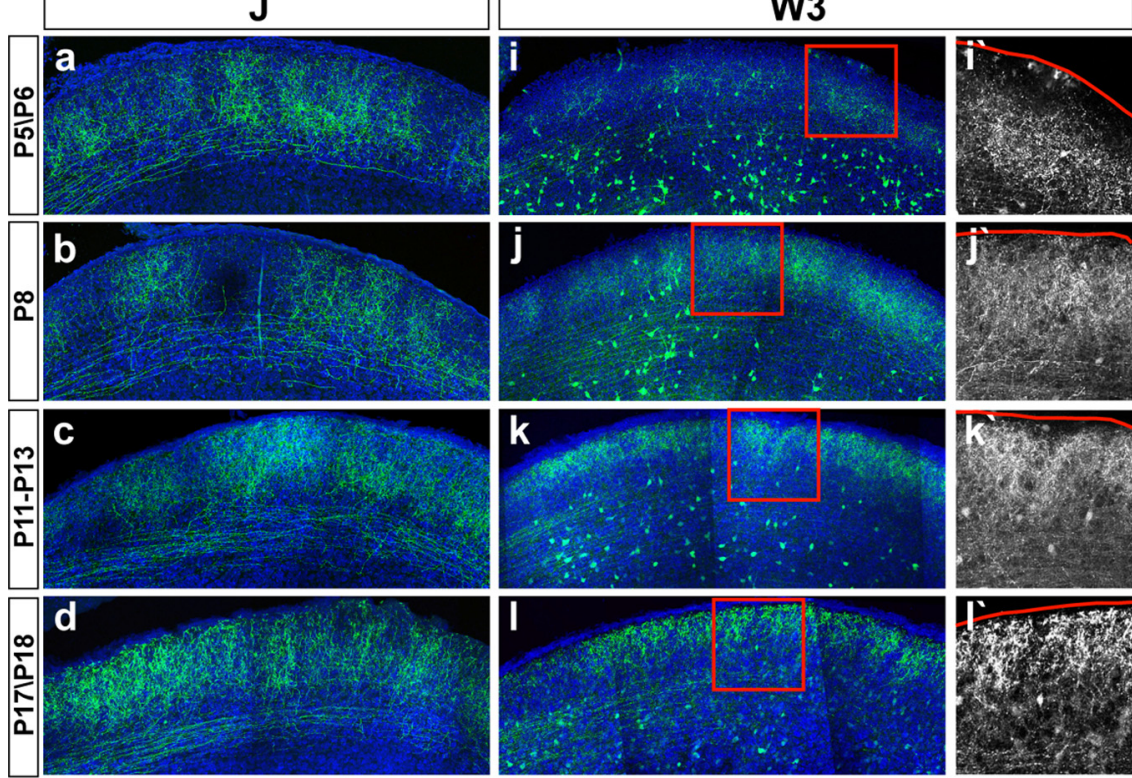

BD
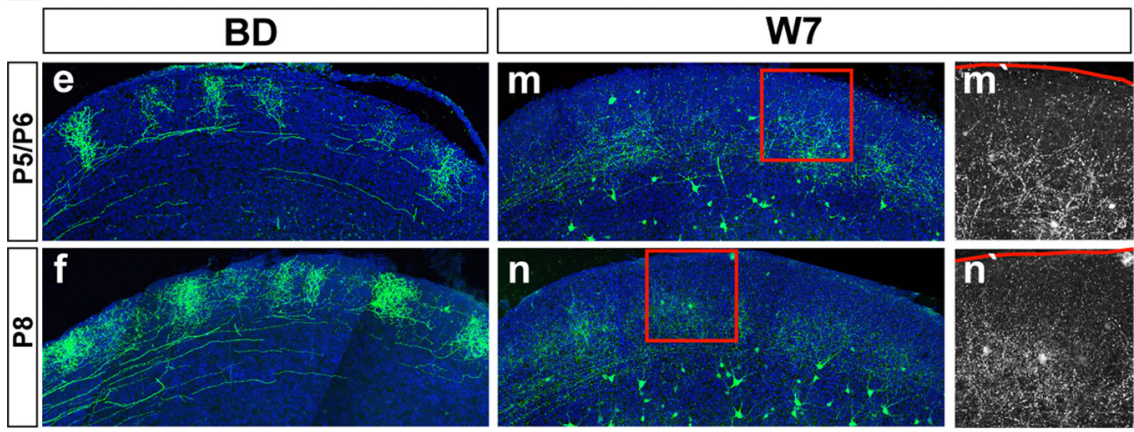

n
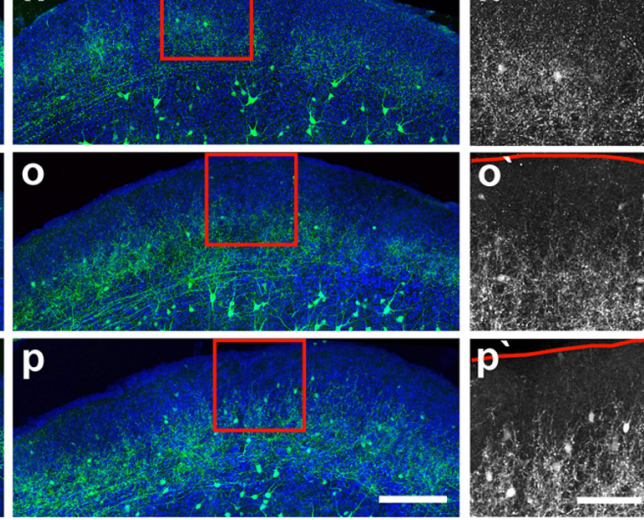

Figure 8. Subtype-specific patterns of axonal development in the superior colliculus. Sagittal sections from P5-P6, P8, P11P13, and P17-P18 mice are shown. Axonal arborization from each RGC subtype was visualized by immunostaining to anti-GFP (green). $\boldsymbol{i}^{\prime}-\boldsymbol{p}^{\prime}$, High magnification of boxes marked in $\boldsymbol{i}-\boldsymbol{p}$ to emphasize distinct patterns of axonal arborization in W3- and W7-RGCs. The pia surface is indicated by a red line. Blue, Cell bodies. Scale bars: (in $\boldsymbol{p}$ ) $\boldsymbol{a}-\boldsymbol{p}, 200 \mu \mathrm{m}$; (in $\boldsymbol{p}^{\prime}$ ) $\boldsymbol{i}^{\prime}-\boldsymbol{p}^{\prime}, 100 \mu \mathrm{m}$.

retinal waves in forming $\mathrm{ON}$ and $\mathrm{OFF}$ circuits in the inner retina. $\mathrm{J} \mathrm{Neu}$ rosci 20:7672-7681.

Berson DM (2008) Retinal ganglion cell types and their central projections. In: The senses: a comprehensive reference (Basbaum AI, Kaneko A, Shepherd GM and Westheimer G, eds), Vol 1, pp 491-520. San Diego: Academic.

Bodnarenko SR, Chalupa LM (1993) Stratification of ON and OFF ganglion cell dendrites depends on glutamate-mediated afferent activity in the developing retina. Nature 364:144-146.

Bodnarenko SR, Yeung G, Thomas L, McCarthy M (1999) The development of retinal ganglion cell dendritic stratification in ferrets. Neuroreport 10:2955-2959.

Buffelli M, Burgess RW, Feng G, Lobe CG, Lichtman JW, Sanes JR (2003) Genetic evidence that relative synaptic efficacy biases the outcome of synaptic competition. Nature 424:430-434.

Caroni P (1997) Overexpression of growth-associated proteins in the neurons of adult transgenic mice. J Neurosci Methods 71:3-9. 


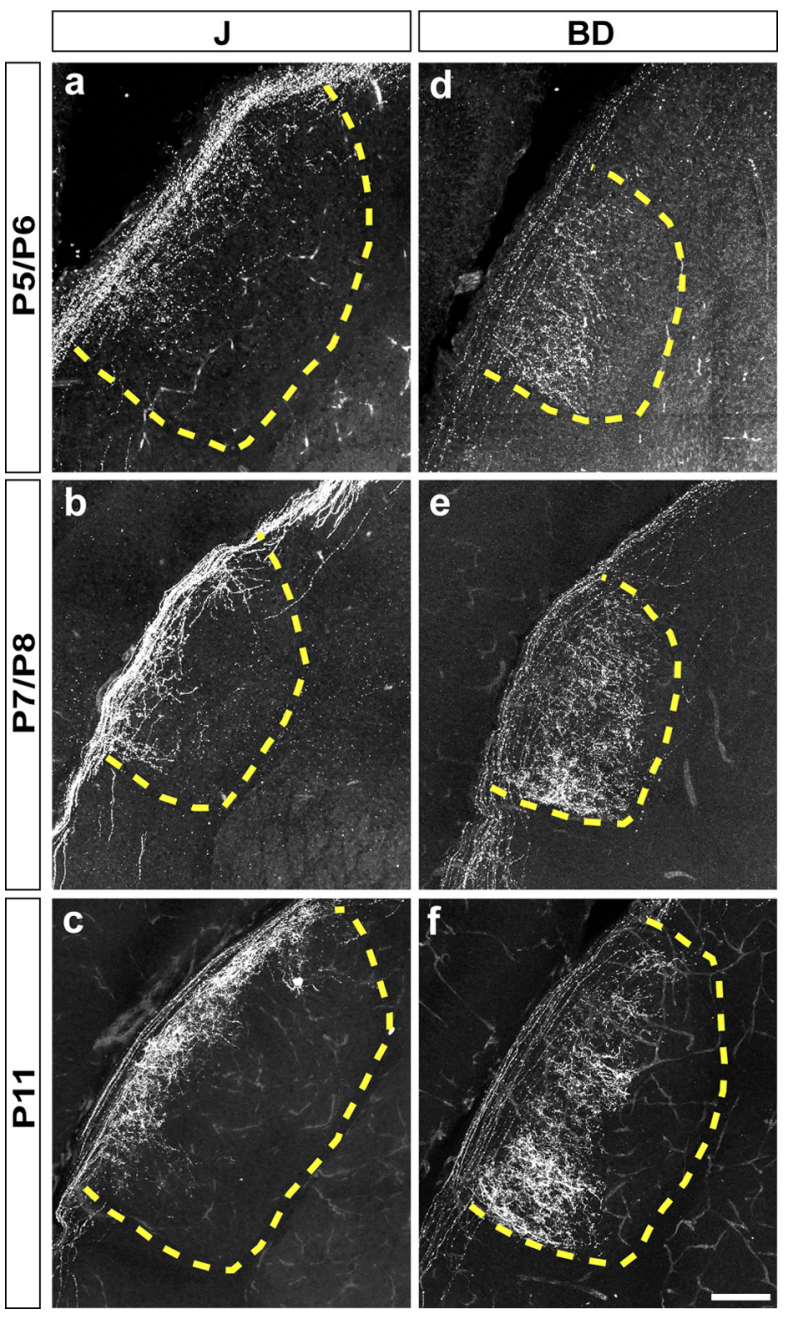

Figure 9. Subtype-specific patterns of axonal development in the lateral geniculate nucleus. Sections were immunostained by anti-GFP (green) at P5-P6, P7-P8, and P11. The dotted lines mark the boundary of LGN. Scale bar: (in $\boldsymbol{f}$ ) $\boldsymbol{a}-\boldsymbol{f}, 100 \mu \mathrm{m}$.
Chalupa LM, Günhan E (2004) Development of On and Off retinal pathways and retinogeniculate projections. Prog Retin Eye Res 23:31-51.

Coombs J, van der List D, Wang GY, Chalupa LM (2006) Morphological properties of mouse retinal ganglion cells. Neuroscience 140:123-136.

Coombs JL, Van Der List D, Chalupa LM (2007) Morphological properties of mouse retinal ganglion cells during postnatal development. J Comp Neurol 503:803-814.

Dacey DM, Packer OS (2003) Colour coding in the primate retina: diverse cell types and cone-specific circuitry. Curr Opin Neurobiol 13:421-427.

Demb JB (2007) Cellular mechanisms for direction selectivity in the retina. Neuron 55:179-186.

Diao L, Sun W, Deng Q, He S (2004) Development of the mouse retina: emerging morphological diversity of the ganglion cells. J Neurobiol $61: 236-249$.

Famiglietti EV Jr, Kolb H (1976) Structural basis for ON-and OFF-center responses in retinal ganglion cells. Science 194:193-195.

Farley FW, Soriano P, Steffen LS, Dymecki SM (2000) Widespread recombinase expression using FLPeR (flipper) mice. Genesis 28:106-110.

Feng G, Mellor RH, Bernstein M, Keller-Peck C, Nguyen QT, Wallace M, Nerbonne JM, Lichtman JW, Sanes JR (2000) Imaging neuronal subsets in transgenic mice expressing multiple spectral variants of GFP. Neuron 28:41-51.

Godement P, Saillour P, Imbert M (1980) The ipsilateral optic pathway to the dorsal lateral geniculate nucleus and superior colliculus in mice with prenatal or postnatal loss of one eye. J Comp Neurol 190:611-626.

Godement P, Salaün J, Imbert M (1984) Prenatal and postnatal development of retinogeniculate and retinocollicular projections in the mouse. J Comp Neurol 230:552-575.

Grubb MS, Thompson ID (2004) Biochemical and anatomical subdivision of the dorsal lateral geniculate nucleus in normal mice and in mice lacking the beta2 subunit of the nicotinic acetylcholine receptor. Vision Res 44:3365-3376.

Hattar S, Liao HW, Takao M, Berson DM, Yau KW (2002) Melanopsincontaining retinal ganglion cells: architecture, projections, and intrinsic photosensitivity. Science 295:1065-1070.

Haverkamp S, Wässle H (2000) Immunocytochemical analysis of the mouse retina. J Comp Neurol 424:1-23.

Haverkamp S, Inta D, Monyer H, Wässle H (2009) Expression analysis of green fluorescent protein in retinal neurons of four transgenic mouse lines. Neuroscience 160:126-139.

Hofbauer A, Dräger UC (1985) Depth segregation of retinal ganglion cells projecting to mouse superior colliculus. J Comp Neurol 234:465-474.

Huberman AD, Manu M, Koch SM, Susman MW, Lutz AB, Ullian EM, Baccus SA, Barres BA (2008) Architecture and activity-mediated refinement of axonal projections from a mosaic of genetically identified retinal ganglion cells. Neuron 59:425-438.

Huberman AD, Wei W, Elstrott J, Stafford BK, Feller MB, Barres BA (2009) Genetic identification of an On-Off directionselective retinal ganglion cell subtype reveals a layer-specific subcortical map of posterior motion. Neuron 62:327-334

Kim IJ, Zhang Y, Yamagata M, Meister M, Sanes JR (2008) Molecular identification of a retinal cell type that responds to upward motion. Nature 452:478-482

Kong JH, Fish DR, Rockhill RL, Masland RH (2005) Diversity of ganglion cells in the mouse retina: unsupervised morphological classification and its limits. J Comp Neurol 489:293-310

Kuffler SW (1953) Discharge patterns and functional organization of mammalian retina. J Neurophysiol 16:37-68.

Lee EC, Yu D, Martinez de Velasco J, Tessarollo L, Swing DA, Court DL, Jenkins NA, Copeland NG (2001) A highly efficient Escherichia coli-based chromosome engineering system adapted for recombinogenic targeting and subcloning of BAC DNA. Genomics 73:56-65.

Ling C, Schneider GE, Jhaveri S (1998) Targetspecific morphology of retinal axon arbors in the adult hamster. Vis Neurosci 15:559-579.

Liu X, Grishanin RN, Tolwani RJ, Rentería RC,

Figure 10. Summary of subtype-specific patterns of dendritic and axonal development. See Results for details. 
Xu B, Reichardt LF, Copenhagen DR (2007) Brain-derived neurotrophic factor and TrkB modulate visual experience-dependent refinement of neuronal pathways in retina. J Neurosci 27:7256-7267.

Masland RH (2001) The fundamental plan of the retina. Nat Neurosci 4:877-886.

Maslim J, Stone J (1988) Time course of stratification of the dendritic fields of ganglion cells in the retina of the cat. Brain Res Dev Brain Res 44:87-93.

Mu X, Klein WH (2004) A gene regulatory hierarchy for retinal ganglion cell specification and differentiation. Semin Cell Dev Biol 15:115-123.

Mumm JS, Williams PR, Godinho L, Koerber A, Pittman AJ, Roeser T, Chien $\mathrm{CB}$, Baier H, Wong RO (2006) In vivo imaging reveals dendritic targeting of laminated afferents by zebrafish retinal ganglion cells. Neuron 52:609-621.

Nassi JJ, Callaway EM (2009) Parallel processing strategies of the primate visual system. Nat Rev Neurosci 10:360-372.

Reese BE (1988) 'Hidden lamination' in the dorsal lateral geniculate nucleus: the functional organization of this thalamic region in the rat. Brain Res 472:119-137.

Rockhill RL, Daly FJ, MacNeil MA, Brown SP, Masland RH (2002) The diversity of ganglion cells in a mammalian retina. J Neurosci 22:3831-3843.

Rowan S, Cepko CL (2004) Genetic analysis of the homeodomain transcription factor Chx10 in the retina using a novel multifunctional BAC transgenic mouse reporter. Dev Biol 271:388-402.

Sachs GM, Schneider GE (1984) The morphology of optic tract axons arborizing in the superior colliculus of the hamster. J Comp Neurol 230:155-167.

Sachs GM, Jacobson M, Caviness VS Jr (1986) Postnatal changes in arborization patterns of murine retinocollicular axons. J Comp Neurol 246:395-408.

Shatz CJ, Sretavan DW (1986) Interactions between retinal ganglion cells during the development of the mammalian visual system. Annu Rev Neurosci 9:171-207.

Siegert S, Scherf BG, Del Punta K, Didkovsky N, Heintz N, Roska B (2009) Genetic address book for retinal cell types. Nat Neurosci 12:11971204.

So KF, Campbell G, Lieberman AR (1990) Development of the mammalian retinogeniculate pathway: target finding, transient synapses and binocular segregation. J Exp Biol 153:85-104.

Stacy RC, Wong RO (2003) Developmental relationship between cholinergic amacrine cell processes and ganglion cell dendrites of the mouse retina. J Comp Neurol 456:154-166.
Sun W, LiN, He S (2002) Large-scale morphological survey of mouse retinal ganglion cells. J Comp Neurol 451:115-126.

Tian N (2008) Synaptic activity, visual experience and the maturation of retinal synaptic circuitry. J Physiol 586:4347-4355.

Tian N, Copenhagen DR (2003) Visual stimulation is required for refinement of ON and OFF pathways in postnatal retina. Neuron 39:85-96.

Völgyi B, Chheda S, Bloomfield SA (2009) Tracer coupling patterns of the ganglion cell subtypes in the mouse retina. J Comp Neurol 512:664687.

Wässle H (2004) Parallel processing in the mammalian retina. Nat Rev Neurosci 5:747-757.

Weng S, Sun W, He S (2005) Identification of ON-OFF directionselective ganglion cells in the mouse retina. J Physiol 562:915923.

Xiao T, Baier H (2007) Lamina-specific axonal projections in the zebrafish tectum require the type IV collagen Dragnet. Nat Neurosci 10: $1529-1537$.

Xu HP, Tian N (2007) Retinal ganglion cell dendrites undergo a visual activity-dependent redistribution after eye opening. J Comp Neurol 503:244-259.

Yamagata M, Sanes JR (1995) Target-independent diversification and targetspecific projection of chemically defined retinal ganglion cell subsets. Development 121:3763-3776.

Yamagata M, Sanes JR (2008) Dscam and Sidekick proteins direct laminaspecific synaptic connections in vertebrate retina. Nature 451:465-469.

Yamagata M, Weiner JA, Dulac C, Roth KA, Sanes JR (2006) Labeled lines in the retinotectal system: markers for retinorecipient sublaminae and the retinal ganglion cell subsets that innervate them. Mol Cell Neurosci 33:296-310.

Yamasaki EN, Ramoa AS (1993) Dendritic remodelling of retinal ganglion cells during development of the rat. J Comp Neurol 329:277-289.

Yonehara K, Shintani T, Suzuki R, Sakuta H, Takeuchi Y, NakamuraYonehara K, Noda M (2008) Expression of SPIG1 reveals development of a retinal ganglion cell subtype projecting to the medial terminal nucleus in the mouse. PLoS One 3:e1533.

Yonehara K, Ishikane H, Sakuta H, Shintani T, Nakamura-Yonehara K, Kamiji NL, Usui S, Noda M (2009) Identification of retinal ganglion cells and their projections involved in central transmission of information about upward and downward image motion. PLoS One 4:e4320. 